\title{
Overcrowding in a neonatal intermediate care unit: impact on the incidence of multidrug-resistant gram-negative organisms
}

Doris Fischer $^{1 *}$ (D, Rolf L. Schlößer ${ }^{1}$, Volkhard A. J. Kempf ${ }^{2,3}$, Thomas A. Wichelhaus ${ }^{2,3}$, Thomas Klingebiel ${ }^{1}$, Sabine Philippi ${ }^{1}$, Linda Falgenhauer ${ }^{4}$, Can Imirzalioglu ${ }^{4}$, Udo Dahl ${ }^{2,3}$, Christian Brandt ${ }^{2,3}$ and Claudia Reinheimer ${ }^{2,3}$

\begin{abstract}
Background: Overcrowding, reduced nurse to patient ratio, limited distance between incubators and absence of microbiological surveillance have been shown to promote spread of multidrug-resistant gram-negative organisms (MDRGN) in patients with birthweight $<1500 \mathrm{~g}$. Patients $>1500 \mathrm{~g}$ treated on an intermediate care unit are unrepresented in recent literature. We therefore intended to present data obtained from a short-term overcrowded neonatal intermediate care unit (NIMCU) at a level III (international categorization) perinatal center at University Hospital Frankfurt, Germany.
\end{abstract}

Methods: During a 25 day overcrowding (OV) and 28 day post-overcrowding period (POST-OV) on NIMCU, epidemiological data obtained from continuously hold microbiological surveillance were investigated and compared to the last 12 months of ward-regular bed occupancy preceding OV (PRAE-OV).

Results: During OV, the number of patients simultaneously treated at the NIMCU increased from 18 to 22, resulting in a reduced bed-to-bed space. Nurse: patient ratio was 4:22 during OV compared to 3:18 during PRAE-OV. Cumulative incidence of MDRGN was $4.7 \%$ in OV and 2.4\% POST-OV compared to $4.8 \%$ to PRAE-OV, respectively, without any significant variations. During OV and POST-OV, septic episodes due to MDRGN were not observed. In one case, potential nosocomial transmission of Enterobacter cloacae resistant to Piperacillin and 3rd/4th generation cephalosporins was observed.

Conclusions: Prevention of nosocomial spread of MDRGN in an overcrowded NIMCU is based on staff's diligent training and adequate staffing. Concise microbiological surveillance should be guaranteed to escort through overcrowding periods. In our setting, impact of bed-to-bed distance on MDRGN transmission seemed to be less strong.

Keywords: Multidrug-resistant gram-negative bacteria, Overcrowding, Neonatal intermediate care unit, Nurse to patient ratio, Infection control, Microbiological surveillance

\section{Background}

The rapid global spread of multidrug-resistant gramnegative organisms (MDRGN) is a serious global health risk, associated to several factors, e.g. traveling to high-prevalence countries (HPC) for MDRGN or contact to healthcare-systems in HPC [1-8]. Since MDRGN frequently cause community and healthcare-associated infections in almost all countries and medical disciplines

\footnotetext{
*Correspondence: doris.fischer@st-vincenz.de

'Department of Pediatrics, Division of Neonatology, University Hospital Frankfurt, St. Vincenz Hospital, Auf dem Schafsberg, 65549 Limburg, Germany Full list of author information is available at the end of the article
}

[9-11], efforts to prevent infections caused by MDRGN should therefore not only address adequate usage of antibiotics and the development of strategies to prevent spread of MDRGN, but also on enhancement of the knowledge of MDRGN transmission, especially in hospital settings. Overcrowding has been shown to promote the spread of the Middle East Respiratory Syndrome coronavirus (MERS-CoV) in medical wards [12-14]. Overcrowding was mentioned as well as one major factor in the spread of severe acute respiratory syndrome (SARS) due to SARS-coronavirus (CoV) in healthcare workers [15]. Transmission of methicillin-resistant 
Staphylococcus aureus (MRSA) is also promoted by overcrowding [16, 17]. In neonatal units overcrowding has also been shown to foster the spread of gram-negative bacteria and central venous lines (CVC) associated bloodstream infections [18]. Overcrowding therefore should be considered to promote transmission and spread of MDRGN on neonatal units.

Although overcrowding in medical wards should be impeded in order to prevent transmission of multidrug-resistant pathogens, it however might be inevitable sometimes $[19,20]$. Due to inalienable reconstruction in June / July 2016, number of simultaneously treated patients at the neonatal intermediate care unit (NIMCU) at the University Hospital Frankfurt (UHF) increased under identical spatial conditions, resulting in an overcrowed NIMCU. This study highlights epidemiological, microbiological and neonatological management in order to give insight of infection control in a short-term overcrowded NIMCU.

\section{Methods \\ Definitions}

Increase of hospital mortality has been attributed to overcrowding [18-21], however, no detailed definition has been formulated. We followed the definition by Gordon et al [22].

PRAE-OV was defined as the one-year-period prior to the overcrowding period with NIMCU running under regular bed-occupancy. PRAE-OV was introduced to calculate the average incidence of MDRGN on NIMCU which is the epidemiological benchmark for $\mathrm{OV}$ and the post-overcrowding observational period (POST-OV), the latter being defined as the 28-day-period following OV.

Nosocomial transmission was given, if neonatal as well as the corresponding mother's MDRGN screening was negative on day of admission and the following neonatal MDRGN screening turned positive. Vertical transmission was given, if baby and mother were tested positive for identical MDRGN species and phenotypical resistance pattern at any location.

MDRGN have previously been defined as Enterobacteriaceae with extended spectrum beta-lactamase (ESBL)phenotype, and Enterobacteriaceae, Acinetobacter baumannii and Pseudomonas aeruginosa resistant against piperacillin, any $3 \mathrm{rd} / 4$ th generation cephalosporin, and fluoroquinolones $+/$ - carbapenems $[7,25]$.

\section{Conditions of overcrowding and the university hospital Frankfurt}

The pediatric intensive care unit (PICU) at UHF had been under construction from calendar week (CW) 23 to CW 26 in 2016. Given the nearly continuous maximally occupancy of NICU beds at any paediatric hospital in the Rhine-Main area, transferring neonates to other NICU/NIMCUs was less likely. Therefore, all neonates meeting the entry criteria for NIMCU were transferred from PICU to NIMCU at UHF. This period took 25 days under which the ward was scheduled under overcrowded conditions. During OV, number of beds increased from $n=18$ to $n=22$; bed to bed-distance decreased to $1.0-1.2 \mathrm{~m}$. Considering that distance between NICU and NIMCU beds has been recommended to be $2 \mathrm{~m}$ at least [23-26], OV resulted in a infectiologically risky setting.

\section{Detection of multidrug-resistant gram-negative organisms and molecular resistance analysis}

All laboratory testing procedures were performed under strict quality-controlled criteria (ISO 15189:2007 standards) and as previsouly described [7]. Detection of genes encoding carbapenemases are routinely performed via PCR analysis and subsequent sequencing from carbapenem resistant Enterobacteriaceae including the genes for carbapenemases genes NDM, VIM, IMP, OXA-48, and KPC [27]. Identification of Acinetobacter baumannii within the Acinetobacter calcoaceticus - Acinetobacter baumannii (ACB) complex was done by a molecular in house procedure for detection of the species-specific carbapenemase OXA-51.

\section{Staffing}

Patients collective on the NIMCU includes neonates needing special neonatal care as defined in recent literature [28] and neonates needing standard paediatric care. On the herein described NIMCU, nurse:patient ratio was intended to follow present recommendations. For 18 patients, the shift teams were composed of at least 3 board certificated neonatal experienced nurses and mostly 1 trainee nurse. During OV, nurse:patient ratio was increased as described below.

\section{Patients' characteristics on the neonatal intermediate care unit}

Patient's entry criteria for NIMCU were a stable circulatory constitution and respiratory status without the need of invasive ventilation neither non-invasive continuous positive airway pressure (CPAP).

At NIMCU, continuous monitoring of heart- and breathing rate and oxygen saturation was performed. Supplementary (high flow) oxygen was available. Alimentation was performed with total or partial parenteral, nutrition via nasogastric tube, baby bottle or breast feeding. Parenteral nutrition was given via central or peripheral venous lines. Feeding of mothermilk and breastfeeding was preferred and supported. During OV and POST-OV, no patient had either external liquor drainage or arterial inserted cannulas. 


\section{Breast feeding policy on the neonatal intermediate care unit}

Nutrition with mother milk and breast feeding is a definitive goal at NIMCU. Staff team members and mothers were instructed and supported by an international board-certificated lactation nurse. In case of MDRGN positive mother, the mother was instructed to use a separate milk pump; her milk was stored in a separate fridge with the intention to avoid MDRGN transmission of potential MDRGN containing mother milk via external contamination of the mothermilk containing baby bottles. If the baby's condition allowed breastfeeding, it was performed like in MDRGN negative mothers. Scheduled MDRGN screening of mothermilk was not done.

\section{Neonatal intermediate care unit staff's hygiene training}

All neonatal staff team members are being trained in hygiene management of neonates at least twice a year. Additionally, one senior pediatrician at NIMCU is designated as duty hygiene officer (DHO) to supervise hygiene procedures. In any case of suspected increase of MDRGN incidence on the ward, an additional ward round was immediately held with staff of the Institute for Medical Microbiology and Infection Control (IMMIC) of UHF in order to evaluate hygiene procedures on the ward,. Further advice or assistance was constantly given by staff of the IMMIC. During OV and POST-OV, no additional staff team training was provided.

\section{Management of multidrug-resistant gram-negative organism-colonized patients}

Care of MDRGN colonized patient was provided by staff wearing gloves and gowns according to the current recommendations by the Commission for Hospital Hygiene and Infection Prevention of the Robert Koch Institute, Berlin, Germany (KRINKO) [29]. In case of detection of Enterobacteriaceae with extended spectrum beta-lactamase (ESBL)-phenotype, and Enterobacteriaceae, Acinetobacter baumannii and Pseudomonas aeruginosa resistant to piperacillin and any 3rd/4th generation cephalosporin or $2 M R G N$, the patient was not separated in single room. Parents need not wear gloves and gowns but were trained in hands hygiene, repeatedly. In case of detection of an aforementioned species with additional resistance to fluoroquinolones and / or to carbapenems, patient was separated in single room or bed-to-bed distance was arranged to $3 \mathrm{~m}$ at least. In these cases, parents were strictly advised to wear gloves and gowns.

\section{Visitors policy and training}

Parents were encouraged to visit their neonate $24 \mathrm{~h}$ a day. The total amount of visitors/baby was limited to two persons. At their first visit, all visitors received a short instruction of the hygienic rules performed by the attending nurse.

\section{Microbiological surveillance for multidrug-resistant gram- negative organisms on the neonatal intermediate care unit}

As announced by the KRINKO in 2012, microbiological screening for detection of multidrug-resistant organisms is recommended for patients on day of admission to NICU or NIMCU as well as weekly routine screening for patients treated at NICU or NIMCU in Germany $[25,26]$. In order to intervene in case of any epidemiological shift exceeding the average MDRGN incidence on the ward, we furthermore set these findings in relation to the MDRGN incidence monthly calculated for the NIMCU since January 2014.

Patients admitted to the Department of Neonatology at UHF were screened for MDRGN, methicillin-resistant Staphylococcus aureus (MRSA) as well as vancomycinresistant Enterococcus faecalis/faecium (VRE) by rectal and throat swabs. Weekly regular infectious disease interdisciplinary rounds were co-hosted by staff of the IMMIC as well as of department of Neonatology in order to ensure continuous active surveillance on the NIMCU.

\section{Molecular characterization of transmitted bacteria}

For whole genome sequencing (WGS), DNA was isolated using the Purelink Genome DNA Mini kit (Thermo Fisher Scientific, Darmstadt, Germany) from overnight cultures according to the manufacturer's instruction. WGS was carried out using an Illumina Nextera XT library with 2x150bp paired-end reads on an Illumina MiSeq instrument (Illumina, San Diego, CA, USA). The raw data was assembled using SPAdes (version 3.0) (1). The assembled contigs were analysed for multilocus sequence types using MLST 1.8 (2) and acquired antibiotic resistance genes using ResFinder (3).

\section{Statistical analysis}

Average incidence of nosocomial MDRGN transmissions in the NIMCU was calculated based on the monthly nosocomial MDRGN incidence of the last 12 months of ward-regular bed occupancy (PRAE-OV). Chi squared test was performed for statistical analysis. 95\% confidence intervals $(95 \% \mathrm{CI})$ for frequencies were calculated based on binomial distribution and used to confirm statistical significance. $P$-value calculations were not used to evaluate statistical significance as it has been criticized for low reliability [30].

\section{Research process}

This study was a prospective observational study escorting a high risk period on a neonatal intermediate care 
unit. Data were obtained and compared to pre- and post high risk period surveillance data. Major endpoint was incidence of MDRGN; variables included nurse to patient ratio and bed- to bed- distance.

\section{Results}

\section{PRAE-overcrowding period}

Based on the 12 months period prior to OV, mean number of patients admitted to the NIMCU was 35 per month, defined as the basic occupancy. During PRAE-OV, the average number of nosocomial transmission of MDRGN amounted to 2 per month, resulting in a cumulative incidence of $4.8 \%(95 \% \mathrm{CI}=2.9-7.3)$. Bed capacity was 18, nurse:patient ratio 1: 4.5-6 (numeri integri 3-4:18). Under these conditions, bed-to-bed distance amounted to $2 \mathrm{~m}$. Parent-child contact was supported with more than $2 \mathrm{~h}$ of kangarooing/day.

\section{Overcrowding period}

Number of NIMCU beds increased from 18 to 22 . This resulted in a decrease of bed-to-bed distance to $1.0-1.2 \mathrm{~m}$; kangarooing-time could not be continuously provided. Considering that the distance between bed-to-bed-distance is as been recommended to be $2 \mathrm{~m}$ at least [19-22], OV was suggested to be a risk setting for transmission of MDRGN. In contrast to PRAE-OV, these patients were merged in one room. Nurse:patient ratio was increased to 1: 4.4-5.5 (4-5:22) in terms of an increased number of board certificated neonatal nurses taking care for all patients with special neonatal care. One additional neonatal trainee nurse was implemented into patients care for babies without the need for special neonatal care. In the following, only the numbers of experienced nurses are mentioned. Numbers of ward physicians or consultants remained unchanged as well as teaching schedules for nurses or students.

In total, 43 patients with a mean birthweight of $2120 \mathrm{~g}$ (mean; range 490-4340 g) were treated on the NIMCU during OV. The ward occupancy therefore increased by almost $147 \%$ compared to the basic occupancy during PRAE-OV. Treatment of 20/43 patients extended into POST-OV.

7 patients were tested positive for MDRGN (Table 1). In two patients (B and E; Table 1) potential nosocomial transmission of MDRGN was observed. Nosocomial transmission of patient $E$ is a particular case. Mother of baby $\mathrm{C}$ was tested positive for Enterobacter cloacae with resistance to $3 \mathrm{rd} / 4$ th generation cephalosporins (E. cloacae Ceph) prior to birth of her baby. She vertically transmitted the strain to her own child and additionally was involved in nosocomial transmission of E. cloacae Ceph to baby E. This nosocomial transmission of E. cloacae Ceph to child $\mathrm{E}$ was most likely associated to misbehavior of mother $\mathrm{C}$ as she provoked direct close skin-to-skin contact to baby $\mathrm{E}$ for several times. One week after skin contact between mother $\mathrm{C}$ and baby $\mathrm{E}$, baby $\mathrm{E}$ was tested positive for $E$. cloacae Ceph for the first time. Resistance pattern of the $E$. cloacae Ceph detected in baby $\mathrm{E}$ were identical to the $E$. cloacae Ceph strains detected in mother $\mathrm{C}$ and baby $\mathrm{C}$ which might indicate bacterial transmission from mother $\mathrm{C}$ to baby $\mathrm{E}$.

In total, cumulative incidence of nosocomial MDRGN transmissions amounted to $n=2$ in 43 patients, resulting in 4.7\% (0.6-15.8) in OV. This did not significantly differ from the cumulative incidence of nosocomial MDRGN transmissions during PRAE-OV $(4.8 \% ; 2.9-7.3)$.

\section{POST-overcrowding period}

In total, 41 patients were treated on NIMCU during POST-OV. Ward occupancy was almost $125 \%$, slightly exceeding the basic occupancy during PRAE-OV. 7 patients were tested positive for MDRGN (Table 2), with two of them being residuals from $\mathrm{OV}$ ( $\mathrm{A}$ and $\mathrm{F}$ ), one pair of twins $\left(\mathrm{H}_{\text {twin1 }}\right.$ and $\left.\mathrm{H}_{\text {twin2 }}\right)$ and two vertical transmissions (I and $\mathrm{J}$ ) - similarly.

Nosocomial transmission of E. cloacae Ceph (patient G; Table 2) occurred in one case. Number of nosocomial MDRGN transmissions amounted to $n=1$ in 41 patients, resulting in a cumulative incidence of $2.4 \%(0.0-12.9)$. This did not significantly differ from the cumulative incidence of nosocomial MDRGN transmissions during PRAE-OV (4.8\%; $2.9-7.3)$ and OV (4.7\%; 0.6-15.8).

\section{Whole genome sequencing results}

The Enterobacter cloacae isolates from the transmission event were whole genome sequenced to investigate their identity. They depicted an identical new multilocus sequence type (allele variants depicted in Table 3), and carried both the AmpC beta-lactamase $b l a_{\text {ACT-7 }}$ and the fosfomycin resistance gene fosA, indicating a clonal spread.

\section{Discussion}

In this study, we implemented the available recommendations concerning neonatal MDRGN transmission into the daily life settings on NIMCU in the scenario of a short-term and high risk overcrowding period.

\section{Infection control}

Overcrowding has formerly been described as a promotor of nosocomial transmission for several pathogens [12-17, 29]. Considering that the NIMCU at UHF was facing a 25-day-overcrowding-period, we prepared in several ways for this precarious period. Prior to OV the hygiene risk associated with this situation was diligently discussed with the NIMCU staff. Parents received fundamental information as well. NIMCU staff underwent scheduled infection control training on e.g. correct 
Table 1 Patients tested positive on NIMCU during OV

\begin{tabular}{llll}
\hline Patient $^{\mathrm{a}}$ & Sex & MDRGN species & Mode of acquisition \\
\hline $\mathrm{A}$ & $\mathrm{m}$ & Escherichia coli ESBL & vertical \\
$\mathrm{B}$ & $\mathrm{m}$ & Enterobacter aerogenes Ceph & nosocomial \\
$\mathrm{C}$ & $\mathrm{m}$ & Enterobacter cloacae Ceph & vertical \\
$\mathrm{D}$ & $\mathrm{f}$ & Enterobacter cloacae Ceph & vertical \\
$\mathrm{E}$ & $\mathrm{m}$ & Enterobacter cloacae Ceph & nosocomial transmitted to baby E by mother of baby C \\
$\mathrm{F}$ & $\mathrm{f}$ & Enterobacter cloacae Ceph & vertical \\
\hline
\end{tabular}

${ }^{a}$ numbered consecutively. Abbreviations: $m$ male, $f$ female, Ceph resistance to 3rd/4th generation cephalosporin, ESBL extended spectrum beta-lactamase

hands hygiene during PRAE-OV, OV and POST-OV. This training was held repeatedly and multidisciplinary by the DHO and by staff of the IMMIC of UHF. Thus, these training units did not exceed the scheduled ones.

Low-threshold and broad access to all issues regarding aspects of infection control arising from $\mathrm{OV}$ and POST-OV was provided. Feedback was given immediately, precisely and constructively in any case, either in a positive or negative respect.

Incidence of MDRGN on our NIMCU did not increase during the OV. We therefore assume our management consisting of active surveillance, staff training as well as adherence to infection control demands has proven to be a successful procedure to escort through overcrowding period and prevent the spread of multidrug-resistant organisms in hospital setting. Nevertheless, according to other influencing factors like staff turnover and to maintain continuous alertness; training, bed side supervision and active surveillance have to be implemented as a substantial part in the care of this challenging patient group not only in special risk situations like overcrowding.

\section{Staffing}

Recently published recommendations for perinatal centers [28] suggest a nurse:patient ratio of 1:1 for neonatal intensive treatment patients, $1: 2$ for neonatal intensive monitored patients (e.g. those with non-invasive ventilation, CVC, pleural drainage) and 1:4 for neonatal special care. In NICUs, caring of more than two patients by the

Table 2 Patients tested positive on NIMCU during POST-OV

\begin{tabular}{|c|c|c|c|}
\hline Patient $^{a}$ & Sex & MDRGN species & Mode of acquisition \\
\hline A & $m$ & Escherichia coli ESBL & vertical \\
\hline $\mathrm{F}$ & f & Enterobacter cloacae Ceph & vertical (OV) \\
\hline G & $\mathrm{m}$ & Enterobacter cloacae Ceph & nosocomial \\
\hline $\mathrm{H}_{\text {twin } 1}$ & $\mathrm{~m}$ & Citrobacter freundii Ceph & vertical \\
\hline $\mathrm{H}_{\text {twin2 }}$ & $\mathrm{m}$ & $\begin{array}{l}\text { Citrobacter freundii Ceph } \\
\text { Acinetobacter baumannii }\end{array}$ & vertical \\
\hline । & $\mathrm{m}$ & Escherichia coli ESBL & vertical \\
\hline J & $\mathrm{m}$ & Escherichia coli ESBL/FQ & vertical \\
\hline
\end{tabular}

anumbered consecutively. Abbreviations: $m$ male, $f$ female, Ceph resistance to 3rd/4th generation cephalosporin, ESBL extended spectrum beta-lactamase, $E S B L / F Q E S B L+$ resistance to fluoroquinolones same nurse increases the risk of nosocomial infections (NI) clearly $[16,21]$.

Ventilatory or circulatory support as well as necessity of CVCs or other invasive catheters is less likely in NIMCU than in NICU patients implicating fewer patients to staff contact and less risk for NI.

However, patients' immunological maturation is still ongoing and host defence against bacteria remains fragile [31]. Prematurity related apnoea-bradycardia-syndrome with the need of frequent tactile stimuli is one of the predominant diseases of the NIMCU patients and regular care procedures are performed 6 to 12 times per day. Moreover, ultrasound examinations are regularly provided and additional patient to staff contact is common e.g. because of teaching issues. The number of patient to staff contacts of an NIMCU patient might therefore exceed the number during his NICU period.

Given this characteristics of a NIMCU patient, the takeover of NICU recommendations for NIMCU seems reasonable, but does not represent daily routine on NIMCU. In our setting, we aimed to reach the nurse:patient ratio of 1:4 at least in the high risk overcrowding period. Though we did not reach the recommended ratio regarding the total amount of NIMCU patients, we were able to provide the 1:4 ratio in terms of one experienced board certificated neonatal nurse for four neonates receiving special care. As this staff management together with the microbiological surveillance mentioned above resulted in an unaltered MDRGN-transmission rate during $\mathrm{OV}$, we were able to

Table 3 Multilocus variants found in Enterobacter cloacae Baby C and Baby E

\begin{tabular}{lll}
\hline Allele & Baby C & Baby E \\
\hline dnaA & 49 & 49 \\
fusA & 69 & 69 \\
gyrB & 20 & 20 \\
leus & 65 & 65 \\
pyrG & 64 & 64 \\
rplB & 4 & 4 \\
dnaA & 6 & 6 \\
\hline
\end{tabular}


underline the pivotal role of adequate staffing on NIMCUs or NICUs.

\section{Bed to bed distance}

An appropriate bed to bed distance seems reasonable to allow easy staff movements around the incubator without contaminating the opposite patient with non-airborne MRE. The question, how narrow would be enough to prevent transmission is not examined, however, the literature recommend $2 \mathrm{~m}$ bed to bed distance for NICUs [32-34]. Moreover, if kangarooing should be provided, $2 \mathrm{~m}$ space is needed to place deckchairs and to allow parents enough space. During OV, kangarooing was less likely and parental presence between two beds was limited. In this special setting, bed-to-bed distance of 1-1.2 m seemed to be sufficient in terms of preventing MRE transmission.

\section{Impact of visitors / parents}

Our results also point out the impact of parental carriage of MDRGN. Considering that 8 to $16 \%$ of the adult Rhine-Main population is colonized with MDRGN [7, 35], we suggest that parents might serve a risk in terms of infection control.

Although pointed out by several information boards and easy accessible dispensers for hand disinfection, hospital visitors seem to be still less aware on the impact of hand hygienic discipline [36]. Limiting access for visitors but not for parents therefore seems reasonable. Regular visits of parents with intense skin to skin contact (e.g. kangooroing) to their newborn child are inevitable for adequate bacterial skin and gut colonization [31].

Though, paternal MDRGN colonization will not be recognized as fathers are not screened and therefore serve as microbiological 'black box'. Nevertheless, even if maternal MDRGN colonization is emerged, many questions may arise in terms of adequate preventive policy, e.g. the management of mother milk remain. Data on incidence, time course, and outcome of MDRGN transmission by breast milk are not available and prospective studies will not be performed due to ethical reasons. Thus, individual adjusted risk management, weighing the benefits of mother milk nutrition for the individual patient (e.g. reduced risk for necrotizing enterocolitis (NEC)) against the probability of MDRGN transmission (either vertical or nosocomial) and potential biological hazard, especially in case of colonization with MDRGN, is recommended [25, 26, 29].

The consideration whether mother milk and breast feeding could be the key incident in materno-fetal (and potential nosocomial) MDRGN transmission cannot be answered up to now and remains critical, particularly in high risk situations such as overcrowding. Impressingly, our study demonstrated that language skills, intellectual or cultural causes or simple lack of time might lead to a violence of hygienic rules; however, the final result might be nosocomial MDRGN transmission. The transmission of $E$. cloacae Ceph between baby $\mathrm{C}$ and baby $\mathrm{E}$ has been verified via molecularbiological techniques. This transmission event shows that unexpected parental misbehavior - e.g. due to language barriers - can counteract any attempt of infection control. This, however, is an immutable factor but shows all the more that infection control is a team game being never at rest [37-39].

Our results might be biased by the fact, that child-to-parent contact including kangooroing was reduced due to less space between beds. Close skin-to-skin contact might increase the MDRGN transmission from parents to their newborn baby. Given the baseline incidence of MDRGN carrier in Germany, there is a theoretical risk for paternal-child bacterial transmission that was probably reduced by limitation of kangarooing during our OV setting.

\section{Conclusion}

The key issues in prevention of nosocomial spread of MDRGN on NIMCUs during overcrowded periods of a NIMCU seems to be an adequate nurse:patient ratio, staff training and concise microbiological surveillance which should be guaranteed to escort through overcrowding periods. In our setting, bed-to-bed distance might not have played a key role. We think that the role of parental MRDGN transmission, transmission via breast milk in particular, and their impact on infection control management on neonatal departments should be in the focus of future investigations.

\section{Abbreviations}

CEO: Chief Executive Officer; Cl: Confidence interval; CLSI: Clinical and Laboratory Standards Institut; CPAP: Continuous Positive Airway Pressure; CVC: Central Venous Lines; CW: Calendar week; DHO: Duty Hygiene Officer; ESBL: Extended-Spectrum Beta-Lactamase; IMC: Intermediate Care Unit; IMMIC: Institute for Medical Microbiology and Infection Control; KRINKO: Commission for Hospital Hygiene and Infection Prevention of the Robert Koch Institute, Berlin, Germany; MALDI-TOF: Matrix-assisted-laser desorption ionization-time of flight analysis; MDRGN: Multidrug resistant Gram-negative bacteria; MERS-CoV: Middle East Respiratory Syndrome coronavirus; MRSA: Methicillin resistant Staphylococcus aureus; NI: Nosocomial infection; NICU: Neonatal Intensive Care Unit; NIMCU: Neonatal Intermediate Care Unit; NU: Neonatal Units; OV: Overcrowding period; POST-OV: Post Overcrowding period; PRAE-OV: Period prior to OV; SARS: Severe Acute Respiratory Syndrome; SARS-CoV: Severe Acute Respiratory Syndrome Coronavirus; UHF: University Hospital Frankfurt; VRE: Vancomycin resistant Enterococcus spp.

Acknowledgments

We thank Christina Gerstmann for excellent technical assistance.

Funding

Not applicable

Availability of data and materials

The datasets used and analysed during the current study are available from the corresponding author on reasonable request. 


\section{Authors' contributions}

DF and CR designed and conducted the study and wrote the manuscript; DF served as principal investigator. CR, DF, SP and UD carried out the study bed-side. CR, VK and TA were involved in the microbiological analysis. LF and $\mathrm{Cl}$ did the molecular characterization of transmitted bacteria.RS, TK and CB did Manuscript-proofreading and substantively revised it. All authors read and approved the submitted version of the manuscript.

\section{Ethics approval and consent to participate}

The study was performed in accordance with the ethical standards laid down in the 1964 Declaration of Helsinki and its later amendments. Ethical approval was given by the ethics committee of Goethe University Frankfurt (File number: 343/16)

\section{Consent for publication}

Not applicable.

\section{Competing interests}

On behalf of all authors, the corresponding author states that there is no competing interest.

\section{Publisher's Note}

Springer Nature remains neutral with regard to jurisdictional claims in published maps and institutional affiliations.

\begin{abstract}
Author details
'Department of Pediatrics, Division of Neonatology, University Hospital Frankfurt, St. Vincenz Hospital, Auf dem Schafsberg, 65549 Limburg, Germany. ${ }^{2}$ Institute of Medical Microbiology and Infection Control, University Hospital Frankfurt, 60590 Frankfurt at the Main, Germany. ${ }^{3}$ University Center for Infectious Diseases (UCI), University Hospital Frankfurt, 60590 Frankfurt at the Main, Germany. ${ }^{4}$ Justus Liebig University, Institute of Medical Microbiology, and German Center for Infection Research (DZIF), Partner site Giessen-Marburg-Langen, Giessen, Germany.
\end{abstract}

Received: 22 December 2018 Accepted: 11 April 2019 Published online: 29 April 2019

\section{References}

1. Lübbert C, Straube L, Stein C, Makarewicz O, Schubert S, Mössner J, et al. Colonization with extended-spectrum beta-lactamase-producing and carbapenemase-producing Enterobacteriaceae in international travelers returning to Germany. Int J Med Microbiol. 2015;305(1):148-56. https://doi. org/10.1016/j.jimm.2014.12.001 PMID: 547265.

2. Tängdén T, Cars O, Melhus A, Löwdin E. Foreign travel is a major risk factor for colonization with Escherichia coli producing CTX-M-type extendedspectrum beta-lactamases: a prospective study with Swedish volunteers. Antimicrob Agents Chemother. 2010;54(9):3564-8. https://doi.org/10.1128/ AAC.00220-10 PMID: 20547788.

3. Kuenzli E, Jaeger VK, Frei R, Neumayr A, DeCrom S, Haller S, et al. High colonization rates of extended-spectrum $\beta$-lactamase (ESBL)-producing Escherichia coli in Swiss travellers to South Asia - a prospective observational multicentre cohort study looking at epidemiology, microbiology and risk factors. BMC Infect Dis. 2014;14:528. https://doi.org/10.1186/1471-2334-14528 PMID: 25270732.

4. Kaspar T, Schweiger A, Droz S, Marschall J. Colonization with resistant microorganisms in patients transferred from abroad: who needs to be screened? Antimicrob Resist Infect Control. 2015;4:31. https://doi.org/10. 1186/s13756-015-0071-6 PMID: 26213620.

5. Hospenthal DR, Crouch HK, English JF, Leach F, Pool J, Conger NG, et al. Multidrug-resistant bacterial colonization of combat-injured personnel at admission to medical centers after evacuation from Afghanistan and Iraq. J Trauma. 2011;71:S52-7. https://doi.org/10.1097/TA.0b013e31822118fb PMID: 21795879.

6. Murray CK, Yun HC, Griffith ME, Thompson B, Crouch HK, Monson LS, et al. Recovery of multidrug-resistant bacteria from combat personnel evacuated from Iraq and Afghanistan at a single military treatment facility. Mil Med. 2009;174(6):598-604 PMID: 19585772.

7. Reinheimer C, Kempf VA, Göttig S, Hogardt M, Wichelhaus TA, O'Rourke F, Brandt C. Multidrug-resistant organisms detected in refugee patients admitted to a university hospital, Germany June-December 2015. Euro
Surveill. 2016;21(2). https://doi.org/10.2807/15607917.ES.2016.21.2.30110 PMID: 26794850

8. Rossolini GM, D'Andrea MM, Mugnaioli C. The spread of CTX-M-type extended- spectrum beta-lactamases. Clin Microbiol Infect. 2008;14(Suppl 1): 33-41 Review. Erratum in: Clin Microbiol Infect. 2008 May;14 Suppl 5:21-4. PMID: 18154526

9. Kiratisin P, Chongthaleong A, Tan TY, Lagamayo E, Roberts S, Garcia J, Davies T. Comparative in vitro activity of carbapenems against major gramnegative pathogens: results of Asia-Pacific surveillance from the COMPACT II study. Int J Antimicrob Agents. 2012;39(4):311-6. https://doi.org/10.1016/j. ijantimicag.2012.01.002 PMID: 223867439.

10. Jia XQ, Pang F, Chen JZ, Jiang LX. Prevalence and clinical distribution of multidrug-resistant bacteria (3537 isolates) in a tertiary Chinese hospital (January 2012-December 2013). Pathol Biol (Paris). 2015;63(1):21-3. https:// doi.org/10.1016/j.patbio.2014.12.002 PubMed PMID: 25553645.

11. Sievert DM, Ricks P, Edwards JR, Schneider A, Patel J, Srinivasan A, et al. National Healthcare Safety Network (NHSN) team and participating NHSN facilities. Antimicrobial-resistant pathogens associated with healthcareassociated infections: summary of data reported to the national healthcare safety network at the Centers for Disease Control and Prevention, 20092010. Infect Control Hosp Epidemiol. 2013;34(1):1-14 PMID: 23221186.

12. Balkhy HH, Perl TM, Arabi YM. Preventing healthcare-associated transmission of the Middle East respiratory syndrome (MERS): our Achilles heel. J Infect Public Health. 2016;9(3):208-12. https://doi.org/10.1016/j.jph.2016.04.006 PMID: 27158023.

13. Cowling BJ, Park M, Fang VJ, Wu P, Leung GM, Wu JT. Preliminary epidemiological assessment of MERS-CoV outbreak in South Korea, may to June 2015. Euro Surveill. 2015;20(25):7-13 Erratum in: Euro Surveill. 2015; 20(26). pii: 21175. PMID: 26132767.

14. Park HY, Lee EJ, Ryu YW, Kim Y, Kim H, Lee H, Yi SJ. Epidemiological investigation of MERS-CoV spread in a single hospital in South Korea, may to June 2015. Euro Surveill. 2015;20(25):pii=21169.

15. Hui DS. Severe acute respiratory syndrome (SARS): lessons learnt in Hong Kong. J Thorac Dis. 2013;5(Suppl 2):S122-6. https://doi.org/10.3978/j.issn. 2072-1439.2013.06.18 PubMed PMID: 23977432.

16. Andersen BM, Lindemann R, Bergh K, Nesheim Bl, Syversen G, et al. Spread of methicillin-resistant Staphylococcus aureus in a neonatal intensive unit associated with understaffing, overcrowding and mixing of patients. J Hosp Infect. 2002;50:18-24.

17. Haley RW, Cushion NB, Tenover FC, Bannerman TL, Dryer D, Ross J, Sánchez PJ, Siegel JD. Eradication of endemic methicillin-resistant Staphylococcus aureus infections from a neonatal intensive care unit. J Infect Dis. 1995; 171(3):614-24. PMID: 7876608.

18. Leistner R, Thürnagel S, Schwab F, Piening B, Gastmeier P, Geffers $C$. The impact of staffing on central venous catheter-associated bloodstream infections in preterm neonates - results of nation-wide cohort study in Germany. Antimicrob Resist Infect Control. 2013;2(1):11. https://doi.org/10. 1186/2047-2994-2-11 PMID: 23557510.

19. Cameron PA. Hospital overcrowding: a threat to patient safety? Med J Aust. 2006;184(5):203-4 PMID: 16515426.

20. Schwab F, Meyer E, Geffers C, Gastmeier P. Understaffing, overcrowding inappropriate nurse:ventilated patient ratio and nosocomial infections: which parameter is the best reflection of deficits? J Hosp Infect. 2012;80(2): 133-9. https://doi.org/10.1016/j.jhin.2011.11.014 PMID: 22188631.

21. Harbarth S, Sudre P, Dharan S, Cadenas M, Pittet D. Outbreak of Enterobacter cloacae related to understaffing, overcrowding, and poor hygiene practices. Infect Control Hosp Epidemiol. 1999;20(9):598-603 PMID: 10501256.

22. Gordon JA, Billings J, Asplin BR, Rhodes KV. Safety net research in emergency medicine: proceedings of the academic emergency medicine consensus conference on "the unraveling safety net". Acad Emerg Med. 2001;8(11):1024-9 Review. PMID: 11691663.

23. American Academy of Pediatrics and American College of Obstetricans and Gynecologists (2002:17-55) Inpatient perinatal care services. Gilstrap LC, Oh W, 5, Elk Grove Village. IL. American Academy of Pediatrics.

24. Cox RA, Rao P, Brandon-Cox C. The use of palivizumab monoclonal antibody to control an outbreak of respiratory syncytial virus infection in a special care baby unit. J Hosp Infect. 2001;48:186-92.

25. Kommission für Krankenhaushygiene und Infektionsprävention beim Robert Koch Institut. Prävention nosokomialer Infektionen bei neonatologischen Intensivpflegepatienten mit einem Geburtsgewicht unter $1.500 \mathrm{~g}$. Epidemiologisches Bulletin. 2012;50:1265-303. 
26. Kommission für Krankenhaushygiene und Infektionsprävention beim Robert Koch Institut: Ergänzende Empfehlung (2012) zur "Prävention nosokomialer Infektionen bei neonatologischen Intensivpflegepatienten mit einem Geburtsgewicht unter $1.500 \mathrm{~g}$. Epidemiologisches Bulletin. 2012;2:13-15.

27. Doyle D, Peirano G, Lascols C, Lloyd T, Church DL, Pitout JD. Laboratory detection of Enterobacteriaceae that produce carbapenemases. J Clin Microbiol. 2012;50:3877-80. https://doi.org/10.1128/JCM.02117-12 PMID: 22993175.

28. Strukturelle Voraussetzungen der perinatologischen Versorgung in Deutschland, Empfehlung AWMF-Registernr.: 087-001 www.awmf.org/ leitlinien Anästh Intensivmed 2016;57;465-471.

29. Kommission für Krankenhaushygiene und Infektionsprävention beim Robert Koch Institut. Risikocharakterisierung intensivmedizinisch behandelter Frühund Neugeborener und Daten zur Ist-Situation in deutschen neonatologischen Intensivpflegestationen. Epidemiologische Bulletin. 2013; 42:1-52.

30. Bankevich A, Nurk S, Antipov D, Gurevich AA, Dvorkin M, Kulikov AS, et al. SPAdes: a new genome assembly algorithm and its applications to singlecell sequencing. J Comput Biol [Internet]. 2012 May 7 [cited 2014 Mar 21]; 19(5):455-77. Available from: http://online.liebertpub.com/doi/abs/10.1089/ cmb.2012.0021.

31. Larsen MV, Cosentino S, Rasmussen S, Friis C, Hasman H, Marvig RL, et al. Multilocus sequence typing of total-genome-sequenced bacteria. J Clin Microbiol. 2012;50(4):1355-61.

32. Zankari E, Hasman H, Cosentino S, Vestergaard M, Rasmussen S, Lund O, et al. Identification of acquired antimicrobial resistance genes. J Antimicrob Chemother [Internet]. 2012 Nov [cited 2014 Mar 20];67(11):2640-4. Available from: http://www.pubmedcentral.nih.gov/articlerender.fcgi?artid= 3468078\&tool=pmcentrez\&rendertype $=$ abstract.

33. Regina Nuzzo. Statistical errors. Nature. 2013;506:150-152. Link: http://www. nature.com/polopoly_fs/1.14700!/menu/main/topColumns/topLeftColumn/ pdf/506150a.pdf (retrieved December $1^{\text {st }}$ 2016).

34. Lindberg E, Adlerberth I, Hesselmar B, et al. High rate of transfer of Staphylococcus aureus from parental skin to infant gut flora. J Clin Microbiol. 2004:42:530-4.

35. Stiller A, Schröder C, Gropmann A, Schwab F, Behnke M, Geffers C, Sunder W, Holzhausen J, Gastmeier P. ICU ward design and nosocomial infection rates: a cross-sectional study in Germany. J Hosp Infect. 2017;95(1):71-5. https://doi.org/10.1016/j.jhin.2016.10.011 PMID: 27884473.

36. White RD, Smith JA, Shepley MM. Recommended standards for newborn ICU design, 8th edition. J Perinatol. 2013;33(Suppl 1):S2-16.

37. White RD. Recommended NICU design standards and the physical environment of the NICU. J Perinatol. 2013;33(Suppl 1):S1.

38. Reinheimer C, Kempf VA, Jozsa K, Wichelhaus TA, Hogardt M, O'Rourke F, et al. Prevalence of multidrug-resistant organisms in refugee patients, medical tourists and domestic patients admitted to a German university hospital. BMC Infect Dis. 2017;17(1):17 PMID: 28056820.

39. Willison-Parry TA, Haidar EA, Martini LG, Coates AR. Handwashing adherence by visitors is poor: is there a simple solution? Am J Infect Control. 2013; 41(10):928-9. https://doi.org/10.1016/j.ajic.2013.01.023 PMID:23608046.

\section{Ready to submit your research? Choose BMC and benefit from:}

- fast, convenient online submission

- thorough peer review by experienced researchers in your field

- rapid publication on acceptance

- support for research data, including large and complex data types

- gold Open Access which fosters wider collaboration and increased citations

- maximum visibility for your research: over $100 \mathrm{M}$ website views per year

At BMC, research is always in progress.

Learn more biomedcentral.com/submissions 